\title{
Osseous Component Present
}

National Cancer Institute

\section{Source}

National Cancer Institute. Osseous Component Present. NCI Thesaurus. Code C54171.

A morphologic finding indicating the presence of bone elements in a tissue sample. 